\title{
Estreitando relacionamentos na educação a distância
}

\author{
Sylvia Constant Vergara*
}

\section{Resumo}

Este artigo privilegia a educação a distância (EAD) e, nela, a questão do relacionamento, muito enfatizada na educação presencial nas figuras do professor e do aluno. Objetiva argumentar que em EAD tal relacionamento também existe e que se expande para além daquele entre professor e aluno, agregando tutores, mentores, equipe técnica, equipe administrativa, enfim, todos aqueles que estão envolvidos no processo. Destaca algumas ações que podem ser desenvolvidas para o estreitamento das relações, todas elas (as ações) nutridas por lealdade, comprometimento, confiança e ajuda mútua.

Palavras-chave: lealdade; comprometimento; confiança; ajuda mútua.

\section{Abstract}

This article privileges long-distance education and, in it, the question of the relationship, very much emphasized in regular education on the figures of the teacher and the student. It has the objective to argue that, in long-distance education, such relationship also exists and expands beyond that one between teacher and student, adding tutors, counselors, technical team, administrative team, and finally, all those that are involved in the process. It detaches some actions that can be developed for the narrowing of the relations, all of them (the actions) nourished by loyalty, commitment, confidence and mutual assistance.

Key words: loyalty; commitment; confidence; mutual assistance.

\section{Introdução}

As tradicionais formas presenciais de educação, sozinhas, não dão conta da empreitada que hoje se coloca para países, estados, municípios, empresas e organizações em geral. Vivemos uma época caracterizada por um turbilhão de inovações tecnológicas, muita pressa, muita incerteza, muita impaciência, muita informação e muita necessidade de pessoas educadas. É nesse contexto que se coloca a educação a distância (EAD).

A história da pedagogia que, tradicionalmente, tem focalizado o ensino presencial, ressalta a importância do relacionamento professor/aluno, o que faz da sala de aula um espaço de ensino/aprendizagem, visto como uma relação (FREIRE, 1996; HUBERT, 1967; LARROYO, 1970; LIMA, 1970). A pedagogia destaca a importância daquele relacionamento na construção do indivíduo e da sociedade da qual ele faz parte. Maturana e Varela (2005), teóricos com foco na biologia, reforçam essa importância ao afirmarem que só criamos o mundo com os outros. E mais: só a aceitação do outro junto a nós permite essa construção comum.

Ao se discutir a EAD, uma das questões que logo emerge é essa, referente ao relacionamento, que envolve racionalidade e, também, o campo dos afetos humanos. Não raro, vê-se tal questão como uma das limitações da EAD e, portanto, com potencial para mitigar seu valor.

A partir da percepção dessa questão, tenho por objetivo, neste artigo, argumentar que o relacionamento professor/aluno também existe na EAD, embora de forma diferenciada e, tal como a educação presencial, expande-se para outras pessoas que, no caso da EAD, compõem as equipes acadêmicas, de produção, de

Doutora em Educação pela UFRJ. Professora da EBAPE/FGV. Endereço: Praia de Botafogo, 190 - sala 533 - Botafogo - CEP 22250- 900 - Rio de Janeiro - RJ. Email: vergara@fgv.br.

Artigo recebido em setembro de 2006 e aceito para publicação em novembro de 2006. 
operação e até a comercial, essa última quando existe. Objetivo, também, identificar o que pode ajudar no estreitamento dos relacionamentos na EAD, e de quais relacionamentos se trata. Apoiada na literatura existente, em conversas com pessoas que produzem EAD e na minha própria experiência como professora em cursos de EAD, explicito reflexões que submeto à apreciação do leitor.

Delimito minhas reflexões ao campo das instituições de ensino. Embora muitas das reflexões sirvam, também, para compreender a EAD no campo empresarial, que nela vem investindo, dada a especificidade desse campo, não o focalizo aqui.

O artigo está estruturado em cinco seções, incluindo essa introdução. Na segunda, explicito o que entendo por EAD. Na terceira, levanto algumas possibilidades e limitações da EAD. Na quarta discuto o cerne do artigo, ou seja, a questão do relacionamento. Concluo na quinta seção.

\section{0 que é ensino a distância (EAD)?}

O Decreto nํ-2.494, de 10-2-1998 (BRASIL, 1998) define EAD como:

uma forma de ensino que possibilita a auto-aprendizagem, com a mediação de recursos didáticos sistematicamente organizados, apresentados em diferentes suportes de informação, utilizados isoladamente ou combinados, e veiculados pelos diversos meios de comunicação.

O Decreto n 5.622, de 19-12-2005 (BRASIL, 2005), que revoga o Decreto n 2.494/98, define EAD como:

modalidade educacional na qual a mediação didático-pedagógica nos processos de ensino e aprendizagem ocorre com a utilização de meios e tecnologias de informação e comunicação, com estudantes e professores desenvolvendo atividades educativas em lugares ou tempos diversos.

A já robusta publicação de livros e artigos sobre o tema revela alguma diversidade sobre o entendimento do que seja EAD (NISKIER, 1999; NUNES, 1993; VEIGA; MOURA; GONÇALVES, 1998). Aqui, vou defini-la como uma modalidade de educação não-presencial, isto é, aquela que não conta com alunos e professores compartilhando uma mesma sala de aula, um mesmo espaço físico. A separação física entre professor e aluno é mediada por algum recurso impresso, mecânico ou eletrônico, que pode facilitar-lhes a interação.

Longe de opor-se ou de ser uma ameaça à educação presencial, a EAD é, apenas, mais uma forma de se educar, mais uma abertura à tradicional relação ensino/aprendizagem. Em educação há um leque de possibilidades. A EAD é mais uma. Ela foi sublinhada pelo International Council on Distance Education (ICDE), realizado em Vancouver, em 1982, e pela Conferência de Viena, realizada em 1999. Nessa conferência já se afirmava que universidades usariam, cada vez mais, EAD conjugada com educação presencial (ARMENGOL; POMERHANZ, 1999).

Um olhar na história nos informará que o conceito não é novo. Muitos, certamente, se lembrarão do "ensino por correspondência" o qual data, até onde se sabe, do final do século XVIII com experiências como as da Universidade de Chicago e do Queen's College (NUNES, 1993). O ensino por correspondência resolvia muitas questões de aprendizado, sobretudo o técnico, mas a interação dos alunos com os professores era pouca ou nenhuma durante o processo, às vezes, limitando-se à avaliação final da aprendizagem.

No fim da década de 1960 do século XX, outros meios começaram a ser utilizados: rádio, televisão, audiocassetes e videocassetes. Nos anos 1970 do século XX, a informática entrou no processo, dando-lhe mais agilidade e permitindo maior interação entre professor e aluno. Hoje, recursos como DVD, CD-ROM e transmissão via satélite nas modalidades videoconferência e teleconferência somam-se aos recursos tradicionais, que não se extinguiram, embora venham perdendo espaço para a Internet, alimentada esta por sucessivos avanços nas tecnologias de informação e comunicação.

A Internet e a Web nos dizem que o céu é o limite. Se a Internet tornou possível a educação on-line, uma vez que permite a ligação de diferentes computadores de marcas e tamanhos, a Web lhe dá inteligência por meio da 
interação entre textos, imagens e sons. Três tecnologias convergentes - computação, microeletrônica e telecomunicações - abrem imensas possibilidades para a EAD. Cada vez mais estão sendo colocadas à disposição do público linguagens interativas. Em EAD, o ambiente Web pode disponibilizar textos, orientações de professores, bibliotecas, avaliações, e realizar chats, fóruns, correio eletrônico (PORTO et al, 2004). Os arquivos podem ter diversos formatos: apresentações, planilhas, textos, animações interativas ou não e outros. Muitos dos materiais utilizados em EAD podem nutrir cursos presenciais.

No Brasil, há menos de uma década estão sendo utilizados recursos tecnológicos que possibilitam o ambiente da sala de aula presencial em ambientes virtuais e, nisto, o país tem se diferenciado até de países ditos desenvolvidos. Muitas universidades americanas e européias, por exemplo, partem do pressuposto de que o aluno é autodidata, disciplinado; logo, cabe-lhe utilizar os recursos da EAD e, assim, construir praticamente sozinho seu saber. Em uma cultura relacional como a brasileira, esse pressuposto cria sérios obstáculos à EAD e, por conta disso, vários programas no Brasil têm enfatizado o relacionamento.

Contudo, a EAD encontra vantagens nos países ditos desenvolvidos. Porque estes realizam sólidos investimentos em ciência e tecnologia, há a possibilidade de criação de mecanismos eficazes que podem otimizar a interação professor/aluno e, como conseqüência, a qualidade do processo ensino/aprendizagem. Por ser assim, essa modalidade de educação desfruta de credibilidade com o público. Por outro lado, ao contrário de outros países em desenvolvimento como a Índia e a China (LE DEVOIR, 2006), no Brasil, a desconfiança ainda é grande, não só pela tradição de cursos presenciais, como pela nem sempre desejável qualidade dos cursos a distância ofertados. Essa circunstância está mudando, no entanto. Já se percebe uma tendência ao crescimento da EAD. Mas como gastos com equipamentos, sistemas e ambiente adequado à implantação de projetos de EAD são altos, eles devem justificar-se.

Via Internet, a EAD exige cuidados no que se refere a questões tecnológicas, modelos pedagógicos, softwares gerenciadores de ambientes virtuais de aprendizagem, capacidade dos equipamentos, legislação, papel da equipe acadêmica, da equipe técnica de produção, da equipe de operações e da equipe comercial (NISKIER, 1999; TESTA; FREITAS, 2002). Entenda-se por equipe acadêmica os professores, os mentores e os tutores; por equipe de produção, os designers, desenhistas, diagramadores e outros; por equipe de operações, o suporte técnico, a logística dos cursos, os gerentes de projetos e a secretaria acadêmica; por equipe comercial, aquela que cuida de custos, retorno financeiro e marketing. Como os cursos presenciais, os cursos a distância não se esgotam nas figuras professor e aluno. Há, ainda, a considerar a confiabilidade que tais cursos devem oferecer.

A EAD pode ser complementada pela educação presencial, em um modelo misto. Pode incluir recursos estéticos na aprendizagem, como desenhos animados, pinturas, filmes e obras literárias, auxiliando o desenvolvimento da sensibilidade e da interação prazerosa. Pode, também, visar diferentes tipos de formação.

É possível que a EAD tenha caráter mais de desenvolvimento do aluno para a aquisição de novas competências profissionais, ou que tenha caráter educacional, o que inclui o desenvolvimento integral do educando. Nesses casos, pode materializar-se em cursos de graduação e de pós-graduação. Há, ainda, a possibilidade da EAD ter orientação mais instrumental. Nesse caso, pode também concretizar-se em cursos de curta duração. Em todas as circunstâncias pode estar adstrita à população de uma determinada escola ou de uma organização que com ela estabeleça parceria ou, ao contrário, pode ser livre, no sentido de abraçar quaisquer indivíduos que por um determinado curso se interessem. A EAD apresenta inúmeras possibilidades e outras tantas limitações.

\section{Possibilidades e limitações da EAD}

Entre as possibilidades da EAD posso mencionar o fato de que permite ao aluno compatibilizar seu curso com suas possibilidades de tempo, realizá-lo no ritmo desejado e em qualquer local disponível, desenvolver independência, comportamento proativo e autodisciplina na busca de seu desenvolvimento. Mas para tanto, é preciso que o aluno monitore a si próprio, para saber pedir ajuda quando necessitar. A EAD exige, portanto, autonomia responsável. 
Se, por um lado, a EAD depende da vontade do aluno de estudar, pesquisar e produzir de forma independente e disciplinada, por outro, fortalece, por meio de múltiplas atividades, a aprendizagem colaborativa, com a troca de informações entre alunos (MAIA; MEIRELLES, 2002). Eis porque é pertinente a formação de turmas. Elas permitem uma construção coletiva que programas individuais comercializados não permitem. Devemos ter em mente que a aprendizagem é uma atividade socialmente construída. O indivíduo dá o "salto" pela reflexão, mas precisa da relação com autores diversos, colegas, professores, tutores, outras pessoas em geral.

Há, ainda, a considerar que os ambientes multimídia interativos, pela possibilidade que oferecem do aluno ter acesso a informações digitalizadas de textos, sons, imagens e gráficos, permitem-lhe apreender o conhecimento de forma eficaz, porque um recurso pode complementar o outro na mensagem que pretende transmitir.

Se grandes são as possibilidades, há limitações também. Podem ocorrer algumas limitações tecnológicas, como a baixa capacidade do computador, a lentidão no acesso e a falta de flexibilidade do programa. Há, ainda, a considerar, as habilidades das pessoas para lidarem com a informática, com o computador em si, com a metodologia da EAD. Outra limitação diz respeito à questão cultural. No Brasil, por exemplo, valorizam-se os contatos face a face; é uma cultura fortemente relacional. O trabalho fisicamente solitário pode ser, então, uma limitação. Temos, também, de considerar que tarefas pouco claras e a ausência de feedback podem ser fatores que trazem limitações à EAD (VASCONCELLOS; BERGAMASCHI, 2001). Feedbacks dizem respeito a observações do aluno e respostas das equipes a essas observações. É uma rua de mão-dupla.

Outra limitação diz respeito à leitura e interpretação de textos e outros códigos lingüísticos, se o aluno não tem essa habilidade desenvolvida e se tem pouco domínio na utilização de recursos de multimídia.

O conteúdo da EAD precisa ser escrito de forma diferente da de um texto impresso, como alerta Morgan (2001). Entretanto, mesmo se cuidando dessa diferenciação, é possível que haja problemas relativos à compreensão dos textos. Tais problemas podem ser mitigados com linguagem clara e simples, embora, plena de conteúdo consistente. Mills (1982, p.233) já nos advertiu que a "prosa empolada e polissilábica" não deve predominar nas ciências sociais. Argumenta que a falta de inteligibilidade não está relacionada à complexidade do assunto nem à profundidade do pensamento. Como Perelman e Olbrechts-Tyteca (2002), Mills (1982) chama a atenção para o fato de que devemos estar atentos ao nosso auditório, ao nosso público.

Na comunicação escrita, talvez haja mais fatores intervenientes entre emissor e receptor. A comunicação nãoverbal, que pode mitigar fatores indesejáveis em um contato presencial, precisa, então, ser substituída por outros recursos que os avanços tecnológicos colocam à disposição. Não é sem razão a afirmação de Libâneo (1991) com referência à educação presen cial, mas igualmente válida para a EAD, de que formas adequadas de comunicação contribuem de maneira desejável para a interação professor/aluno. Isso vale para o professor e para o aluno também. Alunos que têm dificuldade de escrever corretamente, por exemplo, podem trazer ruídos ao processo de comunicação.

Com possibilidades e limitações no processo ensino/aprendizagem, a EAD deve pautar-se por alguns atributos e ações que fortalecem relacionamentos.

\section{A questão do relacionamento}

Hoje em dia, de tantos blogs, chats, orkuts, fóruns e correios eletrônicos, é fácil constatar que as pessoas buscam relacionar-se de uma forma ou de outra. Tendo acesso ao computador, buscas se fazem. Então, poderíamos dizer que fica resolvida a questão do relacionamento na EAD? Não é bem assim, por dois motivos, principalmente. Primeiro, porque na EAD o aluno não escolhe com quem quer relacionar-se. Turmas são formadas, independentemente de sua vontade. Segundo, porque educação (presencial ou a distância) tem seus objetivos específicos.

A educação visa facilitar o autoconhecimento do educando como construtor de sua vida e participante ativo da construção, reconstrução e sustentação da realidade social. Visa ajudar o aluno à realização de valores morais 
que o conduzam à ação responsável como aluno, cidadão historicamente situado e como um ser que busca sentido para sua existência.

Para alcançar os objetivos específicos de um processo educacional, relacionamentos em educação têm contornos particulares. Devem facilitar para o aluno condições que lhe permitam aprender a questionar, a dialogar, a refletir, a criticar, a aprender. Dado que não se pode falar de ensino dissociado de aprendizagem, relacionamentos em EAD devem provocar a curiosidade no aluno e criar-lhe oportunidades para o fortalecimento de habilidades sociais na interação fecunda com outras pessoas.

Montaigne, pensador francês, dizia que "mais vale uma cabeça bem-feita do que bem cheia". Essa sua afirmação é sublinhada por Morin (2004), ao assumir a posição de que a função da escola é ensinar a pensar criticamente. Se vários são os caminhos para que tal intento seja alcançado, certamente, um é aquele que diz respeito ao domínio de metodologias e linguagens diferenciadas, o que inclui a linguagem eletrônica. O desafio é utilizar recursos tecnológicos que apresentem ambientes fomentadores de reflexão.

Educação é algo formativo e situado. Veja-se, como Sainsaulieu e Kirschner (2006) nos lembram, que na era contemporânea as novas tecnologias modificaram as profissões, as funções hierárquicas e técnicas, o funcionamento social e a cultura das organizações. Dessa forma, o aluno precisa estar familiarizado com tecnologias da informática, da eletrônica e da telecomunicação, caso da EAD.

Há, ainda, a considerar que atividades educacionais, como nos ensinou Kilpatrick abordando a educação presencial, devem ter sentido para o aluno, provocar-lhe entusiasmo para a sua realização; devem propor ações que promovam contínua construção e reconstrução de experiências (HUBERT, 1967; LARROYO, 1970).

Vale a pena também lembrar Vygotsky (1988) quando afirmou que, sendo cada pessoa um ser social, relacional e participante de um processo histórico, a construção do conhecimento se dá por meio da interação. O processo é de ensino/aprendizagem por incluir quem ensina, quem aprende e a relação entre eles.

Problemas e soluções de relacionamento existem em cursos de EAD e também nos presenciais. O fato de professor e aluno estarem fisicamente juntos em uma sala de aula não significa inexistência de problemas de relacionamento. Murashima e Longo (2005) destacam, por exemplo, a "invisibilidade" do aluno, expressa no seu silêncio diante de uma fala intimidadora do professor ou provocada pelas divagações do aluno por outro tempo e espaço.

São muitos os atributos que podem estreitar relacionamentos. Ressalto aqueles definidos por Sennett (2005) para o desenvolvimento do caráter de uma pessoa, portanto, para sua educação: lealdade, comprometimento, confiança e ajuda mútua. Tais atributos podem servir como orientadores das ações em um curso de EAD.

Responsáveis acadêmicos, técnicos e administrativos do curso devem ser leais e comprometidos não só com a organização que o oferece, como com os alunos. Estes, por sua vez, necessitam acreditar na idoneidade da organização, ter confiança nela, para que seus esforços de aprendizagem se robusteçam.Tradição, respeitabilidade acadêmica da instituição de ensino, práticas evidenciadas no dia-a-dia da interação, que sejam consistentes com os discursos da instituição, são alicerçadoras de relacionamentos profícuos.

O aluno precisa perceber que a relação na qual está inserido é confiável e legítima. É preciso que haja confiança nos funcionários da secretaria acadêmica que dão informações sobre os aspectos burocráticos e que buscam solucionar problemas daí advindos; confiança na possibilidade de negociar alguma questão importante, sensível para o aluno, com a pessoa certa, que possa decidir; confiança na competência teórica de professores, tutores e mentores; confiança na competência técnica de produtores e de operadores do sistema. A credibilidade se sustenta, entre outros fatores, pelo respeito ao cumprimento de regras, de direitos, de deveres, de métodos de avaliação confiáveis.

Além da lealdade, do comprometimento e da confiança, todos os participantes - professores, mentores, tutores, técnicos, gestores e alunos - farão bem se se ajudarem mutuamente na construção do desempenho de um papel educacional que a todos envolve. É fundamental saber trabalhar em equipe, o que implica relacionamento consequiente e afetivo e respeito pelo saber gerado nas diferentes equipes. 
A grande equipe inclui o pessoal administrativo, coordenadores acadêmicos, técnicos em tecnologia da informação, designers, desenhistas, tutores, professores, mentores e alunos. Não é possível chegar a um resultado final desejado, se não houver uma racional e afetiva rede de relacionamentos entre as pessoas envolvidas. Uma equipe de integração entre as diferentes equipes é uma boa medida. Mas todas têm de ser facilitadoras do processo ensino/aprendizagem, dinamizando respostas a possíveis dúvidas. O diálogo é fundamental. Ele deve revelar a confiança que membros das diferentes equipes têm uns nos outros, resultando em coerência na relação com o aluno.

Por seu turno, o atendimento, tanto o acadêmico quanto o burocrático, precisa ser regular, com estabelecimento de prazos e o respeito a eles. Tal monitoramento deve acontecer, não para exercer coerção, mas para ajudar, para levar mensagens de estímulo.

Do ponto de vista acadêmico, a responsabilidade principal do professor é desenvolver conteúdos; a do tutor é provocar e orientar os alunos para o maior ganho educacional possível; a do mentor é manter a coerência e consistência entre as ações dos tutores. A dos três é provocar desafios incitadores à melhoria crescente da aprendizagem.

O papel do tutor é de extrema relevância nesse processo. A presteza nas respostas ao aluno é fundamental, já que não existe o contato presencial, o "olho no olho". O tutor acompanha e monitora atividades sincrônicas, como os chats, Web TVs e gincanas, e as assincrônicas, como os fóruns de discussão. Tutores devem ter a capacidade de provocar nos alunos a vontade consciente de compartilhamento de reflexões e compreensões e a ação neste sentido e, dessa forma, instigar a construção do conhecimento coletivo. Devem, ainda, provocar no aluno a compreensão de que se ele não faz leitura prévia, se não realiza estudo individual e trabalhos em grupo, perde espaço nos chats. Afinal, a EAD exige autodisciplina, liberdade acompanhada da responsabilidade. É de relevância estar atento a alunos que "desaparecem”. É preciso monitorar, chamá-los, incentivá-los a prosseguir. Demonstrar que se preocupa com ele.

O papel do mentor é, também, de suma importância. Ele mantém uma certa coesão entre os tutores, serve-lhes como orientador, dissipa-lhes dúvidas, promove discussões coletivas, dá e recebe feedback, enfim, ajuda a dar coerência ao curso.

Quanto ao professor, deve ter em mente o papel da educação e, por este iluminado, desenvolver o conteúdo, revisitar e revisar o conhecimento gerado, privilegiar atividades que conformem reflexões individuais e grupais. $\mathrm{O}$ aluno precisa sentir que o professor com ele se relaciona. O "face a face" é substituído por outra energia integradora.

Do ponto de vista burocrático, os alunos precisam vivenciar com os funcionários que os atendem, que lhes dão informação, que lhes fazem exigências documentais, um processo educacional de convivência afetiva, elegante e fecunda em termos de relacionamento. Alunos precisam sentir que são importantes, que seus anseios são considerados, embora nem sempre reivindicações possam ser atendidas. Neste caso, precisam entender por qual motivo.

Não é raro o aluno ter uma dúvida e buscar saná-la com a equipe que lhe vem à mente, seja essa equipe a mais adequada ou não para dar-lhe a resposta pronta de que necessita. Como pelo menos três equipes têm contato direto com os alunos - a de tutores, a de suporte técnico e a secretaria acadêmica -,é natural que sejam as mais demandadas. Nesse caso, quem recebe a mensagem e não tem informações suficientes para respondê-la, não a deve desconsiderar; antes, informar o aluno, em um processo educacional, sobre quem ele deve dirigir-se em casos semelhantes e, ao mesmo tempo, direcionar a mensagem para quem, dentro das equipes, poderá respondê-la adequadamente. Como as respostas dadas aos alunos são escritas, geralmente são sintetizadas; mas precisam ser claras, objetivas e coerentes. 


\section{Para concluir}

Neste artigo focalizo a educação a distância (EAD). Vejo nela potencial contributivo à educação presencial. Ambas são modalidades de educação que, longe de se enfraquecerem mutuamente, podem se ajudar, complementar-se, como podem oferecer opções a quem deseja estudar.

Destaco a questão do relacionamento entre professor e aluno, apontado por muitos como algo que faz a diferença entre educação presencial e EAD, já que nesta há ausência de um contato face a face.

Argumento que tal relacionamento também existe na EAD, embora de forma diferenciada. Amplio tal relacionamento para outros envolvidos em EAD, além do professor e do aluno. Abro para tutores, mentores, designers, desenhistas, equipes administrativas, equipes técnicas, secretaria acadêmica, enfim, para todos aqueles que são responsáveis pelo sucesso de um curso de EAD.

Destaco que relacionamentos em EAD devem ter foco no papel da educação, qual seja o de ajudar a aluno a fortalecer-se como ser pensante, construtor do seu existir e da sociedade que o abriga; a agir de forma responsável como aluno, como cidadão e como alguém que busca sentido para sua existência.

Lembro algumas ações que podem ajudar no estreitamento de relações. Elas dizem respeito à lealdade, ao comprometimento, à confiança e à ajuda mútua. Falo de relacionamentos que ajudem o aluno a crescer, a aprender a aprender, a questionar, a criticar, a ser responsável, a posicionar-se no mundo de forma consciente.

Em uma sociedade impaciente, fugaz como a que vivemos, vale a pena envidar esforços para o fortalecimento da atenção, do aidado e da consciência, a fim de que façamos da EAD mais uma contribuição para nos tornarmos melhores indivíduos e melhores coletividades. 


\section{Referências}

ARMENGOL, M. C.; POMERHANZ, L. S. De Vancouver (1982) a Viena (1999): la educación a distancia toma nuevos rumbos. Revista Ibero americana de Educación à Distancia, Madri, v.2, n.2, dic. 1999.

BRASIL. Decreto no 2.494, de 10 de fevereiro de 1998. Regulamenta 0 art. 80 da Lei no 9.394, de 20 de dezembro de 1996, e dá outras providências. Disponível em:<http://www. planalto.gov.br/ccivil_03/decreto/D2494.htm>Acesso em 30 nov. 2006.

BRASIL. Decreto n- 5.622, de 19 de dezembro de 2005. Regulamenta 0 art. 80 da Lei n 9.394, de 20 de dezembro de 1996, que estabelece as diretrizes e bases da educação nacional. Disponível em: <http://www.planalto.gov.br/ccivil_03/_Ato2004-2006/2005/Decreto/D5622. htm\#art37> Acesso em 30 nov. 2006.

FREIRE, P. Pedagogia da autonomia: saberes necessários à prática educativa. 3.ed. São Paulo: Paz e Terra, 1996.

HUBERT, R. História da pedagogia. São Paulo: Companhia Editora Nacional, 1967.

LARROYO, F. História geral da pedagogia. São Paulo: Mestre Jou, 1970.

LE DEVOIR. Éducation - innovations et formation. Québec, Canada, p.H1-H8, 21 mai 2006.

LIBÂNEO, J. C. Didática. São Paulo: Cortez, 1991.

LIMA, L. O. A escola secundária moderna - organização, métodos e processos. 9.ed. Petrópolis: Vozes, 1970.

MAIA, M. C.; M EIRELLES, F. S. Educação a distância: 0 caso da Open University. RAE Eletrônica, v.1, n.1, p.1-15, jan./jun. 2002.

MATURANA, H. R.; VARELA, F. J. As bases biológicas da compreensão humana. 5.ed. São Paulo: Palas Athena, 2005.

MILLS, C. W. A imaginação sociológica. Rio de Janeiro: Zahar, 1982.

MORGAN, G. Thirteen "must ask"questions about e learning products and services. The Learning Organization: an international journal, V.8, n.5, 2001.

MORIN, E. A cabeça bem-feita. 10.ed. [S.I.]: Bertrand Brasil, 2004.

MURASHIM A, M. K. G.; LONGO, C. FGV Online: um desenho do ensino no traçado da distância. In: I CAFÉ METODOLÒGICO DO PROGRAM A GV LAW, 2005, São Paulo. Anais... São Paulo: FGV, 2005.

NISKIER, A. Educação a distância: a tecnologia da esperança. São Paulo: Loyola, 1999.

NUNES, I. B. Noç̃oes de educação a distância. Revista Educação a Distância, Instituto Nacional de Educação a Distância, Brasília, DF, n.4/5, dez. 1993-abr. 1994.

PERELM AN, C.; OLBRECHTS-TYTECA, L. Tratado da argumentação. São Paulo: Martins Fontes, 2002.

PORTO, C. A. et al. As relações entre confiança, valor e lealdade no contexto de educação a distância. In: XXVIII ENCONTRO NACIONAL DE PÓS-GRADUAÇÃO E PESQUISA EM ADMINISTRAÇÃO, 2004, Curitiba. Anais... Curitiba: Anpad 2004. 1 CD-ROM.

SAINSAULIEU, R.; KIRSCHNER, A. M. Sociologia da empresa - organização, poder, cultura e desenvolvimento no Brasil. Rio de Janeiro: DP\&A, 2006

SENNETT, R. A corrosão do caráter - conseqüências pessoais do trabalho no novo capitalismo. Rio de Janeiro: Record, 2005.

TESTA, M. G.; FREITAS, H. M. Fatores importantes na gestão de programas de educação a distância via Internet: a visão dos especialistas. In: XXVI ENCONTRO NACIONAL DE PÓS-GRADUAÇÃO E PESQUISA EM ADM INISTRAÇÃO, 2002, Salvador. Anais... Salvador: Anpad, 2002.1 CD-ROM .

VASCONCELLOS, L.; BERGAMASCHI, S. Equipes virtuais. In: V SEM INÁRIOS EM ADM INISTRAÇÃO, 2001, São Paulo. Anais... São Paulo: FEA/ISP, jun. 2001

VEIGA, R. T.; M OURA, A. I.; GONÇALVES, C. A. 0 ensino a distância pela Internet: conceito e proposta de avaliação. In: XXII ENCONTRO NACIONAL DE PÓS-GRADUAÇÃO E PESQUISA EM ADM INISTRAÇÃO, 1998, Foz do Iguaçu. Anais... Foz do Iguaçu: Anpad, 1998. 1 CD-ROM.

VYGOTSKY, L. S. A formação social da mente - o desenvolvimento dos processos psicológicos superiores. São Paulo: Martins Fontes, 1988. 